\title{
Memorization practice and academic success in Saudi undergraduate students
}

Memorization practice and academic

success

\author{
Maura Pilotti, Halah Alkuhayli and Runna Al Ghazo \\ Prince Mohammad Bin Fahd University, Al Khobar, Saudi Arabia
}

\begin{abstract}
Purpose - In the present study, the authors examined whether academic performance [grade point average (GPA)] can be predicted by self-reported frequency of memorization and recitation, verbatim memory performance, and self-efficacy in a sample of college students from Saudi Arabia.

Design/methodology/approach - Students' verse memory, word memory, experience with memorization and recitation, as well as general self-efficacy were measured. GPA was provided by the Office of the Registrar. Findings - Verbatim memory performance for individual words and verses moderately predicted GPA.

Research limitations/implications - To be determined is the extent to which memory skills for different materials are related to memorization and recitation practice as well as encoding preferences.

Practical implications - The findings indicate that even though in college a premium is placed on activities that transform the format of the materials to be learned, activities that replicate materials may still be helpful. Social implications - In Western pedagogy, memorization and recitation are considered counterproductive modes of information acquisition. The findings of this study illustrate that retention is an essential processing step upon which the complex cognitive activities that are embedded in college-level curricula rely.

Originality/value - The extant literature illustrates the benefits of exceptional memorization and recitation training. The findings suggest that academic success is positively related to what would be judged as moderate practice, thereby supporting the notion that benefits exist.
\end{abstract}

Keywords Learning, Memorization, Self-efficacy, Culture

Paper type Research paper

\section{Introduction}

The current study examined the contribution of verbatim memory skills, as shaped by past and current memorization and recitation practice, to undergraduate students' learning in the Kingdom of Saudi Arabia (KSA). The study was sparked by a truism, based on classroom observations collected throughout several years of undergraduate-level teaching. Namely, Saudi undergraduate students, who express critical thinking abilities in a variety of venues, often exhibit a proclivity toward rote rehearsal as a mode of preparation for class presentations, written assignments and tests (Alkubaidi, 2019; Almusharraf, 2021; El Alaoui et al., 2019). The latter then translates into their expectation that good performance can be achieved through the exercise of verbatim memory. Not surprisingly, educators in KSA and in the Arab world at large tend to be bewildered by their students' reliance on memorization (Gregory \& Bend, 2019; Hamdan Alghamdi, 2014; Hamza, 2010; McLellan, 2012). Yet, a little prodding as well as relevant issues/topics are generally sufficient to induce such students to demonstrate their critical thinking abilities, express interest in knowing relevant facts and understand background information.

(C) Maura Pilotti, Halah Alkuhayli and Runna Al Ghazo. Published in Learning and Teaching in Higher Education: Gulf Perspectives. Published by Emerald Publishing Limited. This article is published under the Creative Commons Attribution (CC BY 4.0) licence. Anyone may reproduce, distribute, translate and create derivative works of this article (for both commercial and non-commercial purposes), subject to full attribution to the original publication and authors. The full terms of this licence may be seen at http:// creativecommons.org/licences/by/4.0/legalcode.

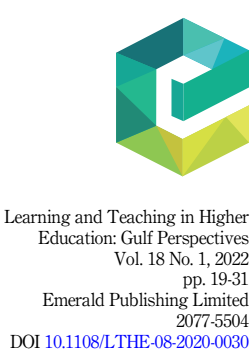

Received 15 September 2020 Revised 5 January 2021 3 April 2021 30 May 2021 31 May 2021 2 September 2021 Accepted 19 September 2021 
LTHE 18,1

One of the topics often debated by educators in KSA is the impact of memorization and recitation practices in primary and secondary education on undergraduate students' learning (Kassem, 2018; Vassall-Fall, 2011). These practices are often seen by Westerners as generating undesirable habits to be discounted in favor of critical thinking (Baumgart \& Halse, 1999; Spier, Leenknecht, Carson, Bichay, \& Faria, 2019), perhaps because memorization and understanding are viewed as both separable and conflicting pursuits. If a little prodding is sufficient for Saudi undergraduate students to demonstrate their critical thinking abilities, could it be that these abilities are merely under-utilized by such students in favor of the more familiar rote learning habits, making the former less visible to educators? If so, what are the benefits of memorization that justify its persistence as information acquisition in such students? These questions motivated the study reported in this paper.

\section{Literature review}

In educational practice, a distinction is often made between rote or verbatim learning and active learning (Cho \& Powers, 2019; Michael, 2007; Yusuf, 2010). Rote learning refers to information that is retained in long-term memory in its original format through exact repetition. Retrieval is assumed to be successful if the original format is reproduced. In active learning, information is submitted to processes that are likely to alter its original format (e.g. application, analysis, evaluation and manipulation) with the goal to solve problems. Yet, rote learning is by no means a passive process. It is an effortful process that requires motivation, persistence and organization (Iqbal \& Ahmad, 2015). It is often accompanied by comprehension, an active process through which newly acquired materials are linked to existing knowledge to be more firmly retained (Frankland \& Bontempi, 2005; Iqbal \& Ahmad, 2015; Yusuf, 2010). Verbatim memories (e.g. new words added to one's vocabulary) are the basic ingredients of critical thinking operations, such as application, analysis, evaluation and manipulation, through which solutions are proposed and problems are solved (Bloom, 1976). Verbatim learning also emphasizes accuracy, which is the cornerstone of the distinction between facts and opinions or, more generally, fiction. This distinction is particularly relevant in professional fields where memory errors can have dire consequences (e.g. false eyewitness identification). Not surprisingly, the act of retrieval strengthens, updates (Larsen, 2018), and altogether alters the learner's knowledge in response to the demands and goals of the present (Bae, Therriault, \& Redifer, 2019; Chan, Manley, \& Ahn, 2020). To wit, verbatim memorization can be conceptualized as making raw materials accessible to acts of active learning, as well as cooperating with acts of active learning to adapt such materials to current goals. Thus, it is reasonable to question whether the conflict between rote memorization and active learning is merely the result of educational models that have artificially prevented their integration by valuing one at the expense of the other.

A teacher-centered education, often assumed to be typical of KSA (Pilotti, Aamir, et al., 2019; Pilotti, El Alaoui, et al., 2019) and of the Arab world more generally (Romanowski et al, 2021), is a top-down model in which the educator is the authority figure whose knowledge and instruction are not to be questioned, and students are the receptacles of such knowledge (Rugh, 2002). The opposite of "the sage on the stage" model (King, 1993) is a student-centered education, typical of the Western world (Komatsu, Rappleye, \& Silova, 2021), which reflects a more equalitarian approach to learning, whereby knowledge is to be sought and evaluated by students with the teacher in the role of facilitator of independent pursuits. The dominance of an educational model in a given geographical area is not a mere historical accident, but rather the byproduct of its ability to fit local traditions in the way information is selected, processed and consumed. The teacher-centered education in schools of the Arab world (Douglass \& Shaikh, 2004; Iqbal \& Ahmad, 2015; Yusuf, 2010) fits the oral tradition of early communities whereby students are expected to commit large segments of text to memory and to reproduce 
them accurately. In this tradition, memorization and recitation are means to preserve scriptures, remember the past, as well as activities conducive to knowledge acquisition, understanding, reasoning and self-discipline (Douglass \& Shaikh, 2004). Yet, one of the byproducts of not questioning authority in a teacher-centered educational model is that memorization and recitation are treated as tools to preserve rather than to advance knowledge. Indeed, if educators' informal observations reflect a kernel of truth, undergraduate students of Arab descent, who possess a teacher-centered educational past, can be described as expressing a rather persistent preference for verbatim learning (Pilotti, Aamir, et al., 2019; Pilotti, El Alaoui, et al., 2019). This preference is likely to reflect a wellknown human disposition toward familiar habits (Gardner, 2012) which can give people the illusion of control, and thus a sense of comfort in challenging situations (Lindbladh \& Lyttkens, 2002). Namely, verbatim learning may be a habit resumed to give the learner influence over the multiple demands of university-level learning as well as confidence in his/ her capabilities to fulfill them. It is often accompanied by the learner's failing to engage spontaneously the very modes of processing that require manipulation and creation of information for problem-solving purposes, as these modes are nebulous in content and form, and less familiar in their use. This mindset, which also appears to apply to Asian students (Baumgart \& Halse, 1999; Breuker, 2018; Park, Nisbett, \& Hedden, 1999; Wu, Carstensen, \& Lee, 2020), does not negate students' ability to think critically (Al-Mahrooqi \& Denman, 2020). It relegates their opportunities to develop and practice critical thinking skills to specific assignments, as well as deprives them of the pleasure to manipulate and create knowledge.

In Islamic religious practices, memorization is seen as the necessary step for the meaning of the Qur'an to unfold in the mind of the learner. Different strategies exist for remembering the verses of the Qur'an (Ikhwanuddin \& Hashim, 2014). Traditional methods generally rely on chunking and repetition through reciting one verse at a time (wahdah), listening (Sama'i), writing (Kitabah), or communal reading (Jama'), which combines reciting and listening. Novel methods may include topical interpretation, which organizes text into meaningful chunks, and mind mapping, which is a visualization technique that relies on diagrams with key concepts serving as memory cues (Al-Mosallam, 2013). Although different strategies exist for remembering the verses of the Qur'an, for the most part, successful memorization tends to emphasize not only the learner's self-discipline but also comprehension and strategic organization of the materials to be acquired (Al-Mosallam, 2013; Ikhwanuddin \& Hashim, 2014; Yusuf, 2010).

At a minimum, the act of retrieving information increases its accessibility. It may even change its meaning and value by enhancing organization (see Congleton \& Rajaram, 2012; Zaromb \& Roediger, 2010). Thus, learning as reproduction may be considered in its pure form a negligible aspect of memory in daily life (Lefrancois, 2019). Learning as reconstruction is characterized by strategic rehearsal, including rote repetition and specialized strategies, used to encode, recollect and preserve information for higher-order cognitive acts, including comprehension, application, analysis, etc. If so, does rehearsal practice (i.e. memorization and recitation) have observable and measurable consequences? Most evidence involves cases of substantial practice. For instance, Iqbal and Ahmad (2015) compared the academic performance of Hafiz-e-Qur'an medical students, who had memorized the entire Qur'an word by word, with non-Hafiz-e-Qur'an medical students matched on key demographic variables. In this study, Hafiz-e-Qur'an students performed better than the matched control participants in physiology, a subject that requires more understanding and critical analysis than cramming facts, whereas no differences were found in anatomy, a subject that relies heavily on memorization of facts. In another study, Roche et al. (2009) had a group of older adults practice rote learning for six weeks, during which they learned 500 words per week of prose, newspaper articles, poetry, etc. Memory performance for verbal materials and brain metabolism measures improved from pre- to post-training. Similarly, Valenzuela et al. (2003)
Memorization practice and academic success

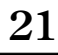


LTHE 18,1

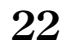

found that repeated activation of memory structures can bring about enhanced memory functioning in older adults. Yet, the latter study did not rely on repetitive rote learning, but mnemonics involving the activation of mental maps stored in long-term memory and selfgenerated associations. More recently, Hartzell et al. (2016) studied the brain morphology of professional Vedic Sanskrit Pandits who memorize and recite Sanskrit text for several hours a day to master its exact pronunciation and content. Their findings indicate that intensive oral memorization and recitation yield selective brain re-organization that mirrors, to a certain degree, that of the older adults in the studies by Roche et al. (2009) and Valenzuela et al. (2003).

Although evidence exists that memorization and recitation practice may improve memory functioning through repeated activation of selective brain areas, we do not know whether ordinary (i.e. more modest in frequency and distributed across time) practice offers performance benefits. In the extant literature, three key questions emerge. First, are the memory skills of Middle Eastern students superior to those of Western-educated students who purportedly had less explicit experience with rote learning? Findings of comparisons of educational cultures that differ considerably in their relative emphasis on rote memory have led to unclear, limited or even contradictory evidence regarding memory skills. For instance, when memory performance of Chinese students, whose education emphasizes rote memorization (Bond, 1991; Liu, 1974), was compared with that of US students, whose education emphasizes problem-solving and other cognitive activities that require manipulation of information, differences favoring Chinese students were not consistently found (see Levy \& Langer, 1994; Liu \& Ma, 1970). When El Alaoui et al. (2019) compared the memory performance of Saudi undergraduate students with norms collected from US students who purportedly did not possess comparable verbatim memory practice and preference, selective differences were found. In this study, participants had to recall lists of words semantically related to a concept (e.g. SLEEP), which was never presented. El Alaoui et al. reported that accuracy, measured as the percentage of words recalled, did not differ, but the probability of falsely recalling the concept words was lower in Saudi students. Saudi students' self-reported past or current frequency of memorization and recitation, however, was not found to be correlated with either memory performance index. If under-reporting is responsible for the absence of correlational evidence, modest practice with memorization and recitation may be understood as inducing attention to the format of the materials presented. Enhanced attention does not improve one's retention or retrieval of verbatim memories but appears to help one discount recollections of items only related to those actually presented (i.e. false memories).

A second question that emerges is whether a preference for verbatim learning impairs students' critical thinking abilities by offering fewer opportunities for practicing such abilities. A few studies have examined the critical thinking abilities of students in the Arab world whose memorization and recitation practice varied within the moderate range, and who displayed a preference for verbatim learning in the classroom. In these studies, US students again served for comparison as they were assumed to have both less practice with, and less of a preference for verbatim learning. McLellan (2012), who examined undergraduate students of the United Arab Emirates, and Pilotti, Aamir, et al. (2019), who examined Saudi undergraduate students, reported lower performance of students whose past education had emphasized verbatim learning. Yet, Pilotti, Aamir, et al. found that motivation (as measured by general self-efficacy) and processing load (as determined by a test read in the second language), predicted the critical thinking performance of Saudi students.

The findings of Pilotti, Aamir, et al. (2019), question whether factors other than critical thinking abilities can be called upon to account for the performance of students with a verbatim learning past and preference. For instance, does practice with rote memorization (within the moderate range) reflect students' discipline and motivation toward academic 
activities that contribute to academic success? The extant literature offers a mixed answer to this question with findings of either a positive (Nield, 2004; Park, 2000; Zakaria, Ahmad, Awang, \& Safar, 2021) or a negative relationship (Albaili, 1994; Keloyan, 2020; van Rossum \& Schenk, 1984) between memorization (as a learning style) and students' achievement. Yet, in most studies, specific preferences for modes of learning rarely reveal the extent to which such modes are actually practiced. Our study contributes to the extant literature by offering evidence on the extent to which memorization and recitation practice, verbatim memory skills and self-efficacy can predict academic success.
Memorization practice and academic success

\section{Methodology}

The present study focused on a single outcome variable, academic achievement (as measured by grade point average, GPA). The goal was to determine the extent of its relationship with three key factors in a sample of Saudi undergraduate students whose practice with memorization and recitation was within a moderate range. The selected factors were (1) selfreported frequency of memorization and recitation, (2) verbatim memory performance and (3) motivation (as indexed by general self-efficacy).

The curricula that defined assessment activities (assignments and tests) contributing to students' GPA at the university in which participants were enrolled required complex cognitive functions (Bloom, 1976; Krathwohl, 2002), such as comprehension, application, analysis, evaluation, and knowledge development, above and beyond retention. Even in Islamic and Arabic Culture courses, where the recitation of memorized chapters of the Qur'an was a key aspect of assessment, class performance involved other activities as well intended to engage an array of complex cognitive functions (i.e. active learning exercises).

Self-efficacy was selected because it is known to affect engagement/motivation variables (e.g. persistence, effort, goal setting, etc.; Alhadabi \& Karpinski, 2020) that can shape performance (Bandura, 1993; Thompson \& Verdino, 2019). Of particular interest here is evidence that beliefs in one's memory capabilities are associated with cognitive effort devoted to memory tests and thus to enhanced memory performance (Wang \& Zhao, 2019).

Verbatim memory skills were assessed both under naturalistic encoding and testing conditions and under conditions less familiar to participants. The former consisted of using the customary task of memorizing verses of the Qur'an (encoding) and then being asked to recite them verbatim (retrieval). The latter consisted of a free recall task involving lists where each word is presented once, little time is allowed for rehearsal, and retrieval is immediate. To ensure sensitivity to individual differences, task difficulty was enhanced by filling each list with words (e.g. bed, rest, awake, tired, dream, wake, snooze, blanket, etc.) semantically associated with a concept word (e.g. SLEEP), which was not presented. In both verse and word memory tests, instructions emphasized recall accuracy.

It was predicted that if individual differences in effort significantly shape performance, one's reported self-efficacy, and the extent of one's practice with memorization and recitation would be positively related to both memory performance and academic achievement. If verbatim memory skills significantly shape academic achievement, even though activities contributing to students' GPA are mostly active learning exercises, verse and word memory performance would predict a portion of the variance in GPA, thereby underlining the dependency of such activities on retention of information.

\section{Participants}

The participants were 122 undergraduate female students of a university in the Eastern Province of KSA. They were enrolled in a mandatory Islamic and Arabic Culture course (IAC II or III). Students were either sophomores or juniors whose ages ranged from 18 to 25. Their majors encompassed all those offered by the selected university. Course selection ensured 
LTHE 18,1

that students' GPA included at least two semesters of classes. The study was conducted under the purview of the Deanship of Research which safeguarded ethical compliance. A comparable sample of male students was unavailable due to gender segregation rules.

\section{Data collection and procedure}

In each course, students were given three Surahs of the Qur'an to memorize (IAC II: 76, 96, and

98; IAC III: 71, 78, and 82), and then were tested on a Surah randomly selected from the

assigned options. Testing required verbatim recitation of the verses of the Surah. A scale from 0 to 10 was used to score performance with 0.25 points deducted every three errors (i.e. deviations from the original script). The obtained score exemplified verse memory performance. To measure word memory, students took a memory test in which they were asked to recall each of 18 lists of 15 semantically related words (Stadler, Roediger, \& McDermott, 1999), immediately after the list was presented. In each list, words were displayed individually on a projector screen, 3 seconds apart in Arabic. Within a list, words appeared in order of strongest to weakest associative strength. Each word was preceded by a 1-s click to alert students of its occurrence.

The word memory test was followed by a brief personal history questionnaire that asked students to report their experiences with memorization (i.e. rote rehearsal used to add information to long-term memory) and recitation (i.e. rote rehearsal used to preserve information already in long-term memory). Students reported (1) the extent of their past (i.e. primary and secondary school) and current (i.e. university) reliance on memorization (RM) on a scale from 0 (never) to 5 (always); (2) the number of chapters of the Qur'an they had memorized before the IAC course enrollment on a scale from 0 to 3 or more $(0-3$; NCQ); (3) the frequency with which they recited an already memorized chapter on a scale from 0 to 3 (i.e. never, yearly or monthly, weekly and daily; FCQ); and (4) their estimates of how long they retained information that they memorized on a scale from "not at all" to " 1 year or more" (0-9; duration of memory records or DMR). Students also completed the New General Self-Efficacy (NGSE) inventory (Chen, Gully, \& Eden, 2001), which contained eight statements of general confidence in one's abilities across a variety of skills, behaviors and situations. Agreement with each statement was measured on a five-point Likert scale from "strongly disagree" to "strongly agree". Cronbach's reliability coefficient (i.e. a measure of internal consistency) was 0.92 .

Memory tests were administered on separate days to minimize fatigue. The NGSE and personal history questionnaires were written in both Arabic and English to enhance students' comfort with the assessment materials. Three independent translators familiar with the construct of self-efficacy and Qur'an memorization techniques were recruited to ensure a culturally intelligible, native and accurate Arabic translation. The translation was driven by the principle of dynamic equivalence (Nida, 2004), according to which "intelligibility is not to be measured merely in terms of whether the words are understandable and the sentences grammatically constructed, but in terms of the total impact the message has on the one who receives it” (Nida, Charles, \& Taber, 1969, p. 22). As per Mulhem et al. (2018), intelligibility was achieved through a consensus model (Scholz, Gutiérrez Doña, Sud, \& Schwarzer, 2002), including back-translations, group discussions and feedback from monolingual individuals (Sperber, 2004).

The study instruments were piloted to ensure that they measured what they were purported to measure. Twenty-four students who did not participate in the study, but were from the same subject pool, filled out both questionnaires and then explained orally their understanding of each item. Responses were later reviewed by two independent raters to determine whether explanations fitted the intended meaning of each item. Four months after the earlier assessment, students filled out the questionnaires again to assess test-retest 
reliability. Pearson correlations were conducted on the pre-ratings and post-ratings of the selected questionnaires. Intra-item correlations ranged from 0.83 to 0.95 for the NGSE questionnaire, and from 0.87 to 0.95 for the personal history questionnaire.

\section{Results}

Descriptive statistics of the key variables are shown in Table 1. In all analyses, results were considered significant at the 0.05 level.

Prior to a stepwise regression analysis to identify the predictors of GPA (serving as the outcome variable), the pattern of associations displayed by GPA was examined through Pearson correlation analyses. Namely, we asked whether GPA was linked to word memory performance, verse memory performance, indices of self-reported memorization and recitation practice, and self-efficacy. A few noteworthy correlations emerged. GPA was positively correlated with word memory $(r=0.212, N=122, p<0.05)$, verse memory $(r=0.458, N=122, p<0.05)$, as well as DMR (i.e. estimated duration of memorized materials; $r=0.196, N=122, p<0.05)$. All other relationships with GPA, including that between GPA and self-efficacy, were not significant.

Based on these exploratory analyses, word memory, verse memory and DMR were selected as predictors in a stepwise regression analysis with GPA as the outcome variable (see Table 2).

Verse memory predicted most of the variance followed by word memory. The ability of verbatim memory performance to account for a portion of the variance in academic achievement underscored the dependency of activities that directly contribute to academic achievement (i.e. assignments and tests) on retention of information. Yet, the percentage of variance in GPA uniquely accounted for by each predictor (as evidenced by the coefficient of determination of semi-partial correlations) illustrated the limits of this dependency. In fact, the percentage of variance in GPA uniquely accounted for by verse memory was $19.54 \%$, and that of word memory was $3.10 \%$.

\begin{tabular}{lc}
\hline Variable & $\begin{array}{c}\text { Mean (standard error } \\
\text { of the mean) }\end{array}$ \\
\hline GPA (0-4) & $3.167(0.050)$ \\
Word memory (\%) & $53.560(1.160)$ \\
Verse memory (\%) & $84.416(2.214)$ \\
GSE (1-5) & $3.860(0.068)$ \\
RM (0-5) & $3.478(0.075)$ \\
\hline & Median \\
\hline DMR (0-9) & A week \\
\hline
\end{tabular}

\begin{tabular}{ll}
\hline NCQ $(0-3)$ & \\
& None \\
& Less than a chapter \\
& A chapter \\
& More than a chapter \\
FCQ $(0-3)$ & Never \\
& Yearly or monthly \\
& Weekly \\
& Daily
\end{tabular}

Frequency distribution

$18.033 \%$

$20.492 \%$

$22.131 \%$

$39.344 \%$

$16.393 \%$

$26.230 \%$

$19.672 \%$

$37.705 \%$
Memorization practice and academic success
Table 1.

Descriptive statistics of key variables $(N=122)$ : GPA, verbatim memory performance, selfefficacy, and selfreported memorization and recitation practice (as measured by the personal history questionnaire) 


\begin{tabular}{llllllll} 
LTHE & Step 1 & $B$ & $\mathrm{SE} B$ & $\beta$ & $t$ & $p$-value & Semi-partial correlation \\
\cline { 2 - 8 } & $\begin{array}{l}\text { Constant } \\
\text { Verse memory* }\end{array}$ & 0.009 & 0.002 & 0.458 & 5.64 & $<0.001$ & 0.458 \\
\cline { 2 - 8 } & Step 2 & $B$ & SE $B$ & $\beta$ & & & \\
\hline $\mathbf{2 6}$ & Constant & 2.041 & 0.211 & & & & 0.442 \\
\hline $\begin{array}{l}\text { Table 2. } \\
\text { Multiple stepwise } \\
\text { regression }\end{array}$ & Verse memory* & 0.009 & 0.002 & 0.443 & 5.531 & $<0.001$ & 0.176 \\
\hline
\end{tabular}

The relationship between verse memory and word memory was not significant when measured through Pearson correlation $(r=0.080, N=122, p>0.05)$. The latter suggests that, albeit both expressions of human memory, the mental operations for memorizing and retrieving verses, and those for memorizing and retrieving isolated words differ. To wit, a verse has a syntactic structure that molds the meaning of individual words to fit a greater whole. Thus, in addition to the processing of phonological information, which serves as the surface form of isolated words, and semantic information, which defines their meaning, a verse requires the processing of a syntactic structure that is integral to its meaning. Additional support for the differentiation of the two types of retention was found in word memory, but not verse memory, being positively correlated with NCQ $(r=0.239, N=122, p<0.05)$ and DMR $(r=0.236, N=122, p<0.05)$. Namely, students' ability to remember isolated words improved with the number of chapters of the Qur'an they had memorized before IAC course enrollment, and with their estimates of the duration of memorized materials.

\section{Discussion}

GPA represents a global criterion of academic achievement, and it is subject to influences from a large array of factors. Our findings illustrate that academic success, as exemplified by GPA, depends to a certain extent on the ability of human memory to develop accurate traces of verbal materials. However, retention alone is not sufficient for academic success to be achieved. Thus, human memory may be described as a support system for other cognitive activities, such as application, analysis, evaluation and knowledge development, all likely to be contributors to academic success.

In the present study, general self-efficacy and self-reported measures of memorization and recitation practice did not significantly account for academic achievement. The absence of a relationship between academic success and general self-efficacy is not surprising. Although most of the evidence links the two variables (Bandura, 1993; Berry \& West, 1993; Kurtovic, Vrdoljak, \& Idzanovic, 2019), findings pointing toward the absence of these links also exist (Ferrari \& Parker, 1992). According to Bandura (1993), self-efficacy is a cognitive phenomenon that can shape self-regulation of thought, behavior and effort exerted across time (indexing motivation and thus determining persistence). The lack of a relationship between GPA and self-efficacy in our study may be merely the byproduct of the limited range of variability of the self-efficacy ratings. Indeed, most scores were above the neutral point.

The null findings involving self-reports of a practice that has both religious and scholastic applications may reflect the need to conceal one's true engagement in the practice or merely one's difficulty to estimate engagement realistically. Although veridical memory performance reflects a student's memory skills, it may also underline discipline, 
motivation, and persistence, all important ingredients of academic achievement, much more than self-reports of memory practice and self-efficacy. Yet, the practice of memorization (encoding) and recitation (rote rehearsal) in Western pedagogy is considered an archetype of a bygone era and thus a counterproductive mode of information acquisition whose use comes at the expense of cognitive processes that involve information manipulation. This view upholds a concern voiced by faculty in the Arab world that if verbatim memory is valued, activities that replicate the material to be learned, such as re-reading and reciting, will be seen by students as enhancing learning. In contrast, activities that transform the format of the material to be learned will be seen as inefficient or distracting. This view contrasts with cognitive information processing models of learning, such as the one exemplified by Bloom's Taxonomy (Bloom, 1976; Krathwohl, 2002), according to which retention of information is a pre-condition for more complex cognitive functions involving manipulation of knowledge. It is also contrary to the stance of prominent Muslim scholars, such as Al-Ghazali (1056-1111), who considered memorization the first step in the process of understanding (Günther, 2006). Our findings are consistent with both the cognitive information-processing model exemplified by Bloom's Taxonomy and Al-Ghazali's stance. Namely, they illustrate that retention is an essential processing step upon which the complex cognitive activities that are embedded in university-level curricula rely. They are also consistent with earlier findings of a relationship between the memorization of the Quran and academic success as measured by GPA (see Ibrahim et al., 2015).

\section{Conclusion}

The present study aimed to understand how a practice embedded in a culture has managed to survive the reputation given to it by Western pedagogy as a counterproductive mode of information acquisition. The study examined whether academic performance (GPA) could be predicted by self-reported frequency of memorization and recitation, verbatim memory performance and motivation (as indexed by general self-efficacy) in a sample of Saudi undergraduate students. Its findings indicate that even though in higher education a premium is placed on activities that transform the format of the materials to be learned, activities that replicate materials, such as re-reading and reciting, may still be helpful. Yet, only a portion of the variance in GPA was accounted for by verbatim memory, thereby underscoring the role of other contributors to academic achievement (e.g. critical thinking skills).

One of the limitations of the current study is its reliance on female participants. Gender differences in human memory may limit the generalizability of its results. Preferences for different memorization techniques may also alter the contribution of verbatim memory to academic success. Moreover, memory performance for other types of materials may be differentially related to past and current encoding practices and preferences.

The current findings encourage a redefinition of how educators view information acquisition in their students and the advice that they impart regarding such modes. Specifically, they help educators to discard the long-established struggle between discouraging memorization and emphasizing active learning, the latter conventionally seen as the ideal means for integrating effectively new information into one's existing body of knowledge as well as for generating knowledge (Vassall-Fall, 2011).

\section{References}

Al-Mahrooqi, R., \& Denman, C. J. (2020). Assessing students' critical thinking skills in the humanities and sciences colleges of a Middle Eastern University. International Journal of Instruction, 13(1), 783-796, doi: 10.29333/iji.2020.13150a.
Memorization practice and academic success

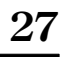




\section{LTHE} 18,1

Al-Mosallam, E. A. (2013, December 22-25). Towards improving Quran memorization using mind maps. [Paper presentation]. Taibah University International Conference on Advances in Information Technology for the Holy Quran and Its Sciences, Madinah, KSA.

Albaili, M. A. (1994). Learning processes and academic achievement of United Arab Emirates college students. Psychological Reports, 74(3), 739-746, doi: 10.2466/pr0.1994.74.3.739.

Alhadabi, A., \& Karpinski, A. C. (2020). Grit, self-efficacy, achievement orientation goals, and academic performance in university students. International Journal of Adolescence and Youth, 25(1), 519-535, doi: 10.1080/02673843.2019.1679202.

Alkubaidi, M. (2019). An action research on EFL writing dilemmas: A case of Saudi students and instructors. Arab World English Journal, 10(3), 151-164, doi: 10.24093/awej/vol10no3.10.

Almusharraf, N. (2021). Perceptions and application of learner autonomy for vocabulary development in Saudi EFL classrooms. International Journal of Education and Practice, 9(1), 13-36, doi: 10. 18488/journal.61.2021.91.13.36.

Bae, C. L., Therriault, D. J., \& Redifer, J. L. (2019). Investigating the testing effect: Retrieval as a characteristic of effective study strategies. Learning and Instruction, 60, 206-214, doi: 10.1016/j. learninstruc.2017.12.008.

Bandura, A. (1993). Perceived self-efficacy in cognitive development and functioning. Educational Psychologist, 28(2), 117-148, doi: 10.1207/s15326985ep2802_3.

Baumgart, N., \& Halse, C. (1999). Approaches to learning across cultures: The role of assessment. Assessment in Education: Principles, Policy \& Practice, 6(3), 321-339, doi: 10.1080/ 09695949992775.

Berry, J. M., \& West, R. L. (1993). Cognitive self-efficacy in relation to personal mastery and goal setting across the life span. International Journal of Behavioral Development, 16(2), 351-379, doi: $10.1177 / 016502549301600213$.

Bloom, B. S. (1976). Human Characteristics and School Learning. McGraw Hill, New York, NY.

Bond, M. H. (1991). Beyond the Chinese face: Insights from Psychology. Oxford: Oxford University Press.

Breuker, M. (2018). Implementation of intercultural, instructional, and methodological aspects in teaching concepts for China. In B. Jansen-Schulz \& T. Tantau (Eds.), Excellent teaching: Principles, Structures, and Requirements (pp. 197-208). Wbv.

Chan, J. C., Manley, K. D., \& Ahn, D. (2020). Does retrieval potentiate new learning when retrieval stops but new learning continues? Journal of Memory and Language, 115, 104150, doi: 10.1016/ j.jml.2020.104150.

Chen, G., Gully, S. M., \& Eden, D. (2001). Validation of a new general self-efficacy scale. Organizational Research Methods, 4(1), 62-83, doi: 10.1177/109442810141004.

Cho, K. W., \& Powers, A. (2019). Testing enhances both memorization and conceptual learning of categorical materials. Journal of Applied Research in Memory and Cognition, 8(2), 166-177, doi: 10.1016/j.jarmac.2019.01.003.

Congleton, A., \& Rajaram, S. (2012). The origin of the interaction between learning method and delay in the testing effect: The roles of processing and conceptual retrieval organization. Memory \& Cognition, 40(4), 528-539, doi: 10.3758/s13421-011-0168-y.

Douglass, S. L., \& Shaikh, M. A. (2004). Defining Islamic education: Differentiation and applications. Current Issues in Comparative Education, 7(1), 5-18.

El Alaoui, K., Aldabbagh, K., Pilotti, M. A. E., Mulhem, H., Salameh, M., Zaghaab, S., \& Al Kuhayli, H. A. (2019). The curious case of the Arabic-English bilingual speaker with substantial rote rehearsal practice. American Journal of Psychology, 132(1), 39-56, doi: 10.5406/amerjpsyc.132.1.0039.

Ferrari, J. R., \& Parker, J. T. (1992). High school achievement, self-efficacy, and locus of control as predictors of freshman academic performance. Psychological Reports, 71(2), 515-518, doi: 10. 2466/pr0.1992.71.2.515. 
Frankland, P. W., \& Bontempi, B. (2005). The organization of recent and remote memories. Nature Reviews Neuroscience, 6(2), 119-130, doi: 10.1038/nrn1607.

Gardner, B. (2012). Habit as automaticity, not frequency. European Health Psychologist, 14(2), 32-36, doi: 10.1037/e544772013-003.

Gregory, L., \& Bend, M. (2019). Modernizing curricula, instruction, and assessment to improve learning. In S. El Tayeb El-Kogali \& C. Krafft (Eds.), Expectations and aspirations: A new framework for education in the Middle East and North Africa (pp. 161-182). The World Bank.

Günther, S. (2006). Be masters in that you teach and continue to learn: Medieval Muslim thinkers on educational theory. Comparative Education Review, 50(3), 367-388, doi: 10.1086/503881.

Hamdan Alghamdi, A. (2014). The road to culturally relevant pedagogy: Expatriate teachers' pedagogical practices in the cultural context of Saudi Arabian higher education. McGill Journal of Education, 49(1), 201-226, doi: 10.7202/1025778ar.

Hamza, A. (2010). International experience: An opportunity for professional development in higher education. Journal of Studies in International Education, 14(1), 50-69, doi: 10.1177/ 1028315308329793.

Hartzell, J. F., Davis, B., Melcher, D., Miceli, G., Movieish, J., Nath, T., ... Hasson, U. (2016). Brains of verbal memory specialists show anatomical differences in language, memory and visual systems. Neuroimage, 131, 181-192, doi: 10.1016/j.neuroimage.2015.07.027.

Ibrahim, E. E. M., Jani, M. S., bin Alias, A., Yasin, R. F. F., \& Zakariyah, L. (2015). Interaction with the Qur'an and self-regulated learning vis-à-vis academic achievement of undergraduate students. International Journal of Current Research and Academic Review, 3(9), 189-197.

Ikhwanuddin, M., \& Hashim, C. N. (2014). Relationship between memorization technique, mastery of the Arabic language, and understanding of the Qur'an. IIUM Journal of Educational Studies, 2(2), 84-97, doi: 10.31436/ijes.v2i2.46.

Iqbal, J., \& Ahmad, A. (2015). Effect of extensive rote learning experience on subsequent academic achievement. Pakistan Armed Forces Medical Journal, 65(4), 510-514.

Kassem, M. A. M. (2018). Improving EFL students' speaking proficiency and motivation: A hybrid problem-based learning approach. Theory \& Practice in Language Studies, 8(7), 848-859, doi: 10. 17507/tpls.0807.17.

Keloyan, M. (2020). Studying the procedure component of learning motives of students with different GPA: (On the examples of students of Khachatur Abovian. Aspu). Main Issues of Pedagogy and Psychology, 17(1), 90-98, doi: 10.24234/miopap.v17i1.368.

King, A. (1993). From sage on the stage to guide on the side. College Teaching, 41(1), 30-35, doi: 10. 1080/87567555.1993.9926781.

Komatsu, H., Rappleye, J., \& Silova, I. (2021). Student-centered learning and sustainability: Solution or problem? Comparative Education Review, 65(1), 6-33, doi: 10.1086/711829.

Krathwohl, D. R. (2002). A revision of Bloom's taxonomy: An overview. Theory into Practice, 41(4), 212-218, doi: 10.1207/s15430421tip4104_2.

Kurtovic, A., Vrdoljak, G., \& Idzanovic, A. (2019). Predicting procrastination: The role of academic achievement, self-efficacy and perfectionism. International Journal of Educational Psychology, 8(1), 1-26, doi: 10.17583/ijep.2019.2993.

Larsen, D. P. (2018). Planning education for long-term retention: The cognitive science and implementation of retrieval practice. Seminars in Neurology, 38(4), 449-456, doi: 10.1055/s-00381666983.

Lefrancois, G. R. (2019). Theories of human learning. Cambridge: Cambridge University Press.

Levy, B., \& Langer, E. (1994). Aging free from negative stereotypes: Successful memory in China and among the American deaf. Journal of Personality and Social Psychology, 66(6), 989-997, doi: 10. 1037/0022-3514.66.6.989.
Memorization practice and academic success 
LTHE 18,1
Lindbladh, E., \& Lyttkens, C. H. (2002). Habit versus choice: The process of decision-making in healthrelated behaviour. Social Science \& Medicine, 55(3), 451-465, doi: 10.1016/S0277-9536(01) 00180-0.

Liu, I. M., \& Ma, H. H. (1970). On the nature of a training trial in verbal learning. Journal of Experimental Psychology, 86(1), 126-127, doi: 10.1037/h0029800.

Liu, S. H. (1974). The use of analogy and symbolism in traditional Chinese philosophy. Journal of Chinese Philosophy, 1(3-4), 313-338, doi: 10.1111/j.1540-6253.1974.tb00654.x.

McLellan, J. (2012). Assessing the critical thinking abilities of United Arab Emirates University business students. Learning and Teaching in Higher Education: Gulf Perspectives, 6(2), 1-17. Retrieved from available at: https://ssrn.com/abstract $=1932038$.

Michael, J. (2007). Faculty perceptions about barriers to active learning. College Teaching, 55(2), 42-47, doi: 10.3200/CTCH.55.2.42-47.

Mulhem, H., El Alaoui, K., Hamdan, A. K., Abdul-Rahim, M. B., Pilotti, M. A., \& Tallouzi, E. A. (2018). Responses to the statements of the new general self-efficacy scale: The case of the ArabicEnglish bilingual speaker. Journal of Cross-Cultural Psychology, 49(3), 470-487, doi: 10.1177/ 0022022118757915.

Nida, E. (2004). Principles of correspondence. In L. Venuti (Ed.), The translation studies reader (pp. 126-140). New York, NY: Routledge.

Nida, E. A., Charles R., \& Taber, C. R. (1969). The theory and practice of translation. Leiden, NL: E. J. Brill.

Nield, K. (2004). Questioning the myth of the Chinese learner. International Journal of Contemporary Hospitality Management, 16(3), 189-196, doi: 10.1108/09596110410531186.

Park, C. C. (2000). Learning style preferences of Southeast Asian students. Urban Education, 35(3), 245-268, doi: 10.1177/0042085900353002.

Park, D. C., Nisbett, R., \& Hedden, T. (1999). Aging, culture, and cognition. The Journals of Gerontology Series B: Psychological Sciences and Social Sciences, 54(2), P75-P84, doi: 10.1093/geronb/54B.2.P75.

Pilotti, M. A., Aamir, S., Al Ghazo, R., \& Al Kuhayli, H. A. (2019). Explicit conditional reasoning performance: An examination of educational past, processing load, and self-efficacy. International Journal of Teaching and Learning in Higher Education, 3(31), 402-412.

Pilotti, M. A., El Alaoui, K., Mulhem, H., \& Al Kuhayli, H. A. (2019). The illusion of knowing in college: A field study of students with a teacher-centered educational past. Europe's Journal of Psychology, 15(4), 789-807, doi: 10.5964/ejop.v15i4.1921.

Roche, R. A., Mullally, S. L., McNulty, J. P., Hayden, J., Brennan, P., Doherty, C. P., . . Mangaoang, M. A. (2009). Prolonged rote learning produces delayed memory facilitation and metabolic changes in the hippocampus of the ageing human brain. BMC Neuroscience, 10(1), 1-17, doi: 10.1186/ 1471-2202-10-136.

Romanowski, M. H., \& Karkouti, I. M. (2021). Transporting problem-based learning to the Gulf Cooperation Council countries (GCC): Using cultural scripts to analyze cultural complexities. Interdisciplinary Journal of Problem-Based Learning, 15(1), 47-63, doi: 10.14434/ijpbl. v15i1.28793.

Rugh, W. A. (2002). Arab education: Tradition, growth and reform. The Middle East Journal, 56(3), 396-414.

Scholz, U., Gutiérrez Doña, B. G., Sud, S., \& Schwarzer, R. (2002). Is general self-efficacy a universal construct? Psychometric findings from 25 countries. European Journal of Psychological Assessment, 18, 242-251, doi: 10.1027//1015-5759.18.3.242.

Sperber, A. D. (2004). Translation and validation of study instruments for cross-cultural research. Gastroenterology, 126(Suppl. 1), S124-S128, doi: 10.1053/j.gastro.2003.10.016. 
Spier, E., Leenknecht, F., Carson, K., Bichay, K., \& Faria, A. M. (2019). Tipping the scales: Overcoming obstacles to support school readiness for all in low-and middle-income countries. Early Years, 39(3), 229-242, doi: 10.1080/09575146.2019.1636571.

Stadler, M. A., Roediger, H. L., \& McDermott, K. B. (1999). Norms for word lists that create false memories. Memory \& Cognition, 27(3), 494-500, doi: 10.3758/BF03211543.

Memorization

practice and academic success

Valenzuela, M. J., Jones, M., Rae, W. W. C., Graham, S., Shnier, R., \& Sachdev, P. (2003). Memory training alters hippocampal neurochemistry in healthy elderly. NeuroReport, 14(10), 1333-1337, doi: 10.1097/01.wnr.0000077548.91466.05.

van Rossum, E. J., \& Schenk, S. M. (1984). The relationship between learning conception, study strategy and learning outcome. British Journal of Educational Psychology, 54(1), 73-83, doi: 10. 1111/j.2044-8279.1984.tb00846.x.

Vassall-Fall, D. (2011). Arab students' perceptions of strategies to reduce memorization. Arab World English Journal, 2(3), 48-69.

Wang, B., \& Zhao, C. (2019). Testing the retrieval effort theory. Swiss Journal of Psychology, 78(3-4), 125-136, doi: 10.1024/1421-0185/a000229.

Wu, Y. J., Carstensen, C. H., \& Lee, J. (2020). A new perspective on memorization practices among East Asian students based on PISA 2012. Educational Psychology, 40(5), 643-662, doi: 10.1080/ 01443410.2019.1648766.

Yusuf, M. (2010). Memorization as a learning style: A balanced approach to academic excellence. OIDA International Journal of Sustainable Development, 1(6), 49-58.

Zakaria, N. A., Ahmad, T., Awang, S. R., \& Safar, A. (2021, July). Determination of Huffaz academic achievement using a binary logistic regression model. Journal of Physics: Conference Series, 1988(1), 012104, doi: 10.1088/1742-6596/1988/1/012104.

Zaromb, F. M., \& Roediger, H. L. (2010). The testing effect in free recall is associated with enhanced organizational processes. Memory \& Cognition, 38(8), 995-1008, doi: 10.3758/MC.38.8.995.

\section{Corresponding author}

Maura Pilotti can be contacted at: maura.pilotti@gmail.com

For instructions on how to order reprints of this article, please visit our website:

www.emeraldgrouppublishing.com/licensing/reprints.htm

Or contact us for further details: permissions@emeraldinsight.com 